\title{
A randomised-controlled trial investigating potential underlying mechanisms of a functionality-based approach to improving women's body image
}

Citation for published version (APA):

Alleva, J. M., Diedrichs, P. C., Halliwell, E., Martijn, C., Stuijfzand, B. G., Treneman-Evans, G., \& Rumsey, N. (2018). A randomised-controlled trial investigating potential underlying mechanisms of a functionalitybased approach to improving women's body image. Body Image, 25, 85-96.

https://doi.org/10.1016/j.bodyim.2018.02.009

Document status and date:

Published: 01/06/2018

DOI:

10.1016/j.bodyim.2018.02.009

Document Version:

Publisher's PDF, also known as Version of record

Document license:

Taverne

Please check the document version of this publication:

- A submitted manuscript is the version of the article upon submission and before peer-review. There can be important differences between the submitted version and the official published version of record.

People interested in the research are advised to contact the author for the final version of the publication, or visit the DOI to the publisher's website.

- The final author version and the galley proof are versions of the publication after peer review.

- The final published version features the final layout of the paper including the volume, issue and page numbers.

Link to publication

\footnotetext{
General rights rights.

- You may freely distribute the URL identifying the publication in the public portal. please follow below link for the End User Agreement:

www.umlib.nl/taverne-license

Take down policy

If you believe that this document breaches copyright please contact us at:

repository@maastrichtuniversity.nl

providing details and we will investigate your claim.
}

Copyright and moral rights for the publications made accessible in the public portal are retained by the authors and/or other copyright owners and it is a condition of accessing publications that users recognise and abide by the legal requirements associated with these

- Users may download and print one copy of any publication from the public portal for the purpose of private study or research.

- You may not further distribute the material or use it for any profit-making activity or commercial gain

If the publication is distributed under the terms of Article $25 \mathrm{fa}$ of the Dutch Copyright Act, indicated by the "Taverne" license above, 


\title{
A randomised-controlled trial investigating potential underlying mechanisms of a functionality-based approach to improving women's body image
}

\author{
Jessica M. Alleva ${ }^{\mathrm{a}, \mathrm{b}, *}$, Phillippa C. Diedrichs ${ }^{\mathrm{b}}$, Emma Halliwell $^{\mathrm{b}}$, Carolien Martijn ${ }^{\mathrm{a}}$, \\ Bobby G. Stuijfzand ${ }^{\mathrm{c}}$, Georgia Treneman-Evans ${ }^{\mathrm{b}}$, Nichola Rumsey ${ }^{\mathrm{b}}$ \\ a Department of Clinical Psychological Science, Maastricht University, Maastricht, The Netherlands \\ ${ }^{\mathrm{b}}$ Centre for Appearance Research, University of the West of England, Bristol, United Kingdom \\ c Jean Golding Institute, University of Bristol, Bristol, United Kingdom
}

\section{A R T I C L E I N F O}

\section{Article history:}

Received 27 November 2017

Received in revised form 19 February 2018

Accepted 23 February 2018

Available online 6 March 2018

\section{Keywords:}

Body functionality

Body image

Body complexity

Body-self integration

Body appreciation

Intervention

\begin{abstract}
A B S T R A C T
Focusing on body functionality is a promising technique for improving women's body image. This study replicates prior research in a large novel sample, tests longer-term follow-up effects, and investigates underlying mechanisms of these effects (body complexity and body-self integration). British women $(N=261)$ aged $18-30$ who wanted to improve their body image were randomised to Expand Your Horizon (three online body functionality writing exercises) or an active control. Trait body image was assessed at Pretest, Posttest, 1-week, and 1-month Follow-Up. To explore whether changes in body complexity and body-self integration 'buffer' the impact of negative body-related experiences, participants also completed beauty-ideal media exposure. Relative to the control, intervention participants experienced improved appearance satisfaction, functionality satisfaction, body appreciation, and body complexity at Posttest, and at both Follow-Ups. Neither body complexity nor body-self integration mediated intervention effects. Media exposure decreased state body satisfaction among intervention and control participants, but neither body complexity nor body-self integration moderated these effects. The findings underscore the value of focusing on body functionality for improving body image and show that effects persist one month post-intervention.
\end{abstract}

(c) 2018 Elsevier Ltd. All rights reserved.

\section{Introduction}

Negative body image is characterised by negative feelings, cognitions, behaviours, and perceptions regarding an individual's own body (Thompson, Heinberg, Altabe, \& Tantleff-Dunn, 1999). Negative body image is common among women (e.g., approximately $30 \%$ of women report body dissatisfaction; Fallon, Harris, \& Johnson, 2014) and can have serious consequences across key areas of living, including psychological and physical health (e.g., disordered eating, physical inactivity), social life and relationships (e.g., social anxiety, avoidance of social activities), and education and work (e.g., curtailed academic achievements and career aspirations; Cash, Jakatdar, \& Williams, 2004; Cooley \& Toray, 2001; Grogan, 2006; Halliwell, Diedrichs, \& Orbach, 2014; Paxton, Neumark-Sztainer,

\footnotetext{
* Corresponding author at: Department of Clinical Psychological Science, Maastricht University, P.O. Box 616, 6200 MD Maastricht, The Netherlands.

E-mail address: Jessica.Alleva@maastrichtuniversity.nl (J.M. Alleva).
}

Hannan, \& Eisenberg, 2006). For these reasons, negative body image has been considered a public health concern, and governments and researchers have called for the dissemination of effective interventions (Paxton, 2015).

Recent research suggests that recognising and appreciating the functionality of one's body can be a fruitful approach for improving body image (Webb, Wood-Barcalow, \& Tylka, 2015). Body functionality describes everything that the body is able to do, encompassing functions related to the domains of (a) internal processes (e.g., digesting food, healing from a cold), (b) physical capacities (e.g., walking, swimming), (c) bodily senses and sensations (e.g., seeing, experiencing pleasure), (d) creative endeavours (e.g., dancing, gardening), (e) self-care (e.g., sleeping, eating), and (f) communication with others (e.g., body language, shared laughter; Alleva, Martijn, Van Breukelen, Jansen, \& Karos 2015). Given that the majority of extant intervention techniques designed to improve body image focus on aspects related to physical appearance (Alleva, Sheeran, Webb, Martijn, \& Miles, 2015), complementing these techniques 
with those emphasising body functionality could lead to more effective interventions.

The present research had two aims: (a) to investigate whether focusing on body functionality leads to improvements in body image; and (b) to investigate mechanisms that could explain how focusing on body functionality leads to improvements in body image. We discuss each of these aims in turn, below.

\subsection{Focusing on body functionality to improve body image}

Initial evidence for the benefits of focusing on body functionality comes from qualitative and correlational research. Interviews with children and women with a positive body image have shown that they emphasise the functionality of their body and strive to take care of their bodies to keep them functioning well (Frisén \& Holmqvist, 2010; McHugh, Coppola, \& Sabiston, 2014; WoodBarcalow, Tylka, \& Augustus-Horvath, 2010). Further, based on her interviews with girls and women across the lifespan, Piran (2016) identified positive experiences of body functionality (e.g., engaging in joyful physical activity) as fundamental to the development and maintenance of positive embodiment. Scholars have also proposed that fitness and yoga-based programmes, as well as some forms of dance, lead to improvements in body image by shifting individuals' focus to their body functionality (e.g., Cook-Cottone, Kane, Keddie, \& Haugli, 2013; Mahlo \& Tiggemann, 2016; Swami \& Tovée, 2009; Tiggemann, Coutts, \& Clark, 2014). Alleva, Tylka, and Kroon Van Diest (2017) have also shown that appreciating the functionality of one's body is associated with various aspects of a more positive body image and well-being (e.g., broadly conceptualising beauty, self-esteem), and is inversely associated with various aspects of a more negative body image and ill-being (e.g., self-objectification, depression).

The impact of focusing on body functionality has also been tested experimentally. In two initial studies, Alleva, Martijn, Jansen, and Nederkoorn (2014) delivered a single brief online writing exercise to female and male undergraduates and women aged 30-50. Participants were either asked to describe what their body can do (functionality focus), what their body looks like (appearance focus), or their route to the university or shopping centre (control focus) using at least 100 words. Undergraduate men who described their body functionality experienced improved functionality satisfaction at immediate Posttest. Further, the 30- to 50-year-old women in the functionality group experienced improved functionality satisfaction at 1-week Follow-Up. In contrast, the undergraduate women did not experience any improvements as a result of describing their body functionality. Alleva et al. proposed that a stronger manipulation might be necessary for college-aged women, who may be more accustomed to viewing their body from an appearance-based perspective (Fredrickson \& Roberts, 1997).

In a third study, Alleva, Martijn et al. (2015) developed a more elaborate one-week programme, Expand Your Horizon, comprised of three online writing exercises, wherein participants describe the various functions of their body and why they are personally meaningful. Each writing exercise focused on two different domains of body functionality. In this study, women aged 18-30 who were screened for having a negative body image were randomised to Expand Your Horizon or an active control programme. Relative to the control, women who completed Expand Your Horizon experienced improved appearance satisfaction, functionality satisfaction, and body appreciation at immediate Posttest and 1-week Follow-Up. Further, at Posttest and 1-week Follow-Up, they also experienced reductions in trait self-objectification: the tendency to view and evaluate one's body based predominantly on its physical appearance, from a third-person observer perspective (Fredrickson \& Roberts, 1997).
Last, in a recent experiment by Mulgrew, Stalley, and Tiggemann (2017), women aged 17-35 were randomised to complete a single brief online exercise wherein they wrote 10 positive statements about either their body functionality or their physical appearance, and its contribution to their well-being. The body functionality task covered the domains of physical capacities, internal processes, and communication with others. Mulgrew et al. found that women in both groups experienced improved appearance satisfaction and functionality satisfaction at immediate Posttest (no control group or Follow-Up measurements were included in this study).

Collectively, these findings suggest that focusing on body functionality is both related to a healthier body image and can also cause improvements in body image. The present study will extend this research by testing the Expand Your Horizon programme in a different sample (women based in England), and so will determine the replicability of this programme in a sample outside the Netherlands (Alleva et al., 2014; Alleva, Martijn et al., 2015). It will also examine the sustainability of the effects by testing whether the effects of focusing on body functionality persist at 1-month Follow-Up.

\subsection{Mechanisms that could explain how focusing on body functionality improves body image}

In addition to investigating whether focusing on body functionality can improve body image, it is important to explore how these improvements may occur. Investigating the potential underlying mechanisms could help us to better understand how body image is shaped and how it can more effectively be improved. Alleva et al. (2014), Alleva, Martijn et al. (2015) proposed that, in line with objectification theory (Fredrickson \& Roberts, 1997), focusing on body functionality could improve body image by counteracting the harmful tendency to view one's own body based predominantly on its physical appearance rather than its functioning. In the current research, we investigated two additional possible mechanisms. Namely, that focusing on body functionality leads to improvements in body image via increased body complexity and body-self integration.

The first mechanism is inspired by research on self-complexity, where it is assumed that knowledge about the self is represented by multiple cognitive structures referred to as self-aspects (Linville, 1985,1987). Self-complexity is a structural property of the selfconcept and concerns the number of distinct self-aspects that comprise the self-concept (Linville, 1985, 1987). Linville (1985, 1987) proposed that individuals can vary in their level of selfcomplexity. For example, a woman lower in self-complexity might view herself in terms of being a researcher and mother, whereas a woman higher in self-complexity might view herself in terms of being a researcher, mother, activist, gamer, painter, etc. Linville also proposed that higher levels of self-complexity can be beneficial because they can 'buffer' the impact of negative experiences on the self-concept. To demonstrate, if the woman lower in selfcomplexity receives a rejection letter from a journal, she is likely to feel more negatively given that her role as a researcher comprises a proportionally larger part of her self-concept. If the woman higher in self-complexity were to receive the same letter, she would likely feel less negatively about herself given that her role as a researcher comprises a proportionally smaller part of her self-concept. Thus, individuals higher in self-complexity will respond with smaller fluctuations in affect or self-appraisal following unpleasant experiences compared to individuals lower in self-complexity (Linville, 1985, 1987). Research on self-complexity has largely confirmed Linville's predictions (see Koch \& Shepperd, 2004, for a review).

Scholars have proposed that knowledge about the body can also be represented in terms of multiple cognitive structures, or bodyaspects, collectively comprising the body-concept (Cash, 2011). In line with the construct of self-complexity, individuals may vary in 
their level of body complexity: the number of distinct body-aspects comprising the body-concept (cf. Harrison, 2006). For example, a woman lower in body complexity might view her body only in terms of weight and shape, whereas a woman higher in body complexity might view her body in terms of weight, shape, stamina, artistic abilities, expressive capacities, etc. To the best of our knowledge, only two prior studies have investigated body complexity: In two cross-sectional studies, Harrison (2006) found that higher levels of television viewing predicted lower body complexity in White U.S. adolescents. It was proposed that television programmes often provide a narrow representation of society (e.g., concerning 'ideal' bodies; Grabe, Ward, \& Hyde, 2008) that can limit the scope of girls' and boys' developing self- and body-concepts. Harrison also proposed that television viewing may reduce time spent on other activities that could broaden the self- and body-concepts via realworld experiences.

Although Harrison's (2006) studies provide valuable information about the possible impact of media consumption on the developing body-concept, they did not investigate the potential beneficial roles of body complexity that would be predicted by Linville's (1985, 1987); theorising and related research (Koch \& Shepperd, 2004). Paralleling this research, we propose that higher levels of body complexity should protect individuals from the impact of negative experiences on the body-concept. For example, exposure to beauty-ideal media imagery (depicting thin, toned, attractive young women) has been shown to decrease women's body satisfaction (Grabe et al., 2008) and could thus be conceptualised as an experience that can negatively affect women's body-concept. A woman higher in body complexity should be less vulnerable to the impact of such experiences on her body-concept given that any impact will affect a smaller proportion of her bodyconcept.

Within the context of Expand Your Horizon, focusing on body functionality could lead to increases in body complexity by helping individuals to broaden the complexity of their body-concept. Instead of focusing on their body in terms of its physical appearance, recognising the numerous functions that their body performs could help them to integrate functionality-related body-aspects into their body-concept. Further, focusing on body functionality in a holistic manner (i.e., not restricted to any one domain or specific body functions) can further enrich individuals' representation of their body-concept. In turn, increased body complexity could lead to improvements in body image over time by protecting individuals from negative experiences on their body-concept, especially those that frequently occur such as via exposure to beauty-ideal media imagery (Grabe et al., 2008). Increased body complexity could also lead to improvements in body image more directly, for example as the body-concept would comprise a greater number of aspects from which individuals could derive appreciation.

In addition to body complexity, we also investigated the potential role of body-self integration in the relationship between focusing on body functionality and improvements in body image. Body-self integration is the degree to which the body-concept is integrated with the self-concept (cf. Goldenberg \& Shackelford, 2005). Thus, whereas body complexity concerns the structural properties of the body-concept, body-self integration concerns the relationship between the body-concept and the self-concept. There is some qualitative and correlational evidence to suggest that body-self integration is related to body image and well-being. For example, in her interviews with girls and women across the lifespan, Piran (2016) found that positive embodiment was characterised by experiencing a sense of connection between the body and self. For instance, participants described feeling "at home" or "at one" with their body (p. 48). In contrast, disrupted embodiment was characterised by experiencing a sense of alienation of the body from the self, whereby participants described their body as a "separate, 'other' territory," or "living 'from the head up"' (p. 48). Piran's findings are in line with other qualitative research showing that girls and boys (Frisén \& Holmqvist, 2010) and women (WoodBarcalow et al., 2010) with a positive body image experience a sense of connection between the body and self. Bode, van der Heij, Taal, and van de Laar (2010) have also shown that, in individuals with rheumatic diseases, experiencing the body as separate from the self - rather than in harmony with the self - is associated with lower self-esteem, and disease-related characteristics and cognitions (e.g., greater pain intensity, feelings of helplessness).

In the context of this study, focusing on body functionality could increase body-self integration as individuals learn to recognise and appreciate the ways in which their body functions are integral to the self and personally meaningful. This notion has been reflected in prior research by Alleva, Martijn et al. (2015), where participants who completed Expand Your Horizon expressed sentiments such as, "My body can dance... Dancing has always been a big part of my life, it helps me to forget everything and enjoy the moment," and "I can listen... This allows me to help people and they can vent to me. This is important to me, it allows me to help my mother when she is going through difficult times." These predictions are also in line with the embodiment model (Menzel \& Levine, 2011), which proposes that engaging in embodying activities leads to a sense of connection between the mind and body that directly promotes a more positive body image. In the present study, reflecting on one's body functionality may elicit these effects without physically engaging in activities at the present moment. Developing a functionality-based focus could also help make body-self connections salient during daily activities, thus enhancing their impact on body image.

Last, similar to body complexity, higher body-self integration might protect individuals from the impact of negative experiences on their body image. This, in turn, could enhance or protect body image over time. For example, when exposed to beautyideal media imagery, a woman high in body-self integration might think, "My whole body, including its functions, is integral to who I am. That's more important than simply being skinny." In other words, given the connection between the body- and self-concepts, individuals might be more driven to protect their body image. Indeed, individuals with a positive body image have been found to practice protective filtering, whereby information that can positively affect their body image is 'filtered in' and information that can negatively affect their body image is 'filtered out' (Frisén \& Holmqvist, 2010; Tylka \& Wood-Barcalow, 2015a; Wood-Barcalow et al., 2010). Higher body-self integration could motivate these protective tendencies.

\subsection{The present study}

This study investigated whether focusing on body functionality leads to improvements in body image. Prior experimental research has suggested this is the case (Alleva et al., 2014; Alleva, Martijn et al., 2015). However, the present study attempted to replicate these findings in a novel sample (British women) and investigated whether effects persisted at a longer-term follow-up (1-month). This study also investigated two potential mechanisms that can explain how focusing on body functionality leads to improvements in body image. We hypothesised that participants in the functionality group, compared to those in the active control group, would experience improvements in body image at Posttest, and that these improvements would persist at 1-week and 1-month Follow-Up. We expected that improvements in body image would be mediated by body complexity and body-self integration. We also predicted that body complexity and body-self integration would moderate the impact of exposure to beauty-ideal media imagery on participants' body image. Exposure to beauty-ideal media imagery was 
chosen as a proxy for negative experiences that can affect body image, given the wealth of research demonstrating such effects and that media exposure lends itself to experimental designs (Grabe et al., 2008).

\section{Method}

\subsection{Participants}

A sample size calculation indicated that at least 180 participants would be needed, assuming a medium effect size (cf. Alleva, Martijn et al., 2015), a two-sided significance level of 5\%, and 80\% power. Fig. 1 shows participant flow through the study. Participants were 261 women aged $18-30$ years $\left(M_{\mathrm{age}}=22.79, S D=3.75\right)$ with an average body mass index (BMI) of $23.55(S D=5.48)$. They identified as White or White British (87.4\%), Asian or Asian British (4.2\%), Mixed (5.2\%) or other background (1.6\%), Black or Black British (1.0\%), or did not provide an answer (0.5\%). Their highest completed education level was some university education (33.5\%), bachelor's degree (23.0\%), high school diploma or equivalency certificate $(19.9 \%)$, master's degree $(12.0 \%)$, graduate degree $(2.6 \%)$, associate's degree (1.0\%), another background (7.3\%), or they had not completed high school $(0.5 \%)$. They identified as heterosexual
(83.2\%), bisexual (9.4\%), other (3.7\%), lesbian (1.6\%), or did not provide an answer (2.1\%). This demographic information is based on the sample at Posttest $(n=191)$, when this information was collected.

\subsection{Measures}

2.2.1. Multidimensional Body-Self Relations Questionnaire Body Areas Satisfaction Subscale (Brown, Cash, E Mikulka, 1990; Cash, 2000)

The Body Areas Satisfaction Subscale contains nine items assessing participants' satisfaction with aspects of their appearance (e.g., weight) from 1 = very dissatisfied to 5 = very satisfied. Scores are averaged; higher scores reflect greater appearance satisfaction. This subscale has shown internal consistency and 1-month test-retest reliability in women (Cash, 2000). In this study, Cronbach's alpha at Pretest, Posttest, 1-week Follow-Up, and 1-month Follow-Up was $.79, .87, .88$, and .91 , respectively.

\subsubsection{Body Esteem Scale - Physical Condition Subscale (Franzoi E' Shields, 1984)}

The Physical Condition Subscale comprises nine items assessing participants' feelings towards body attributes (e.g., health, energy

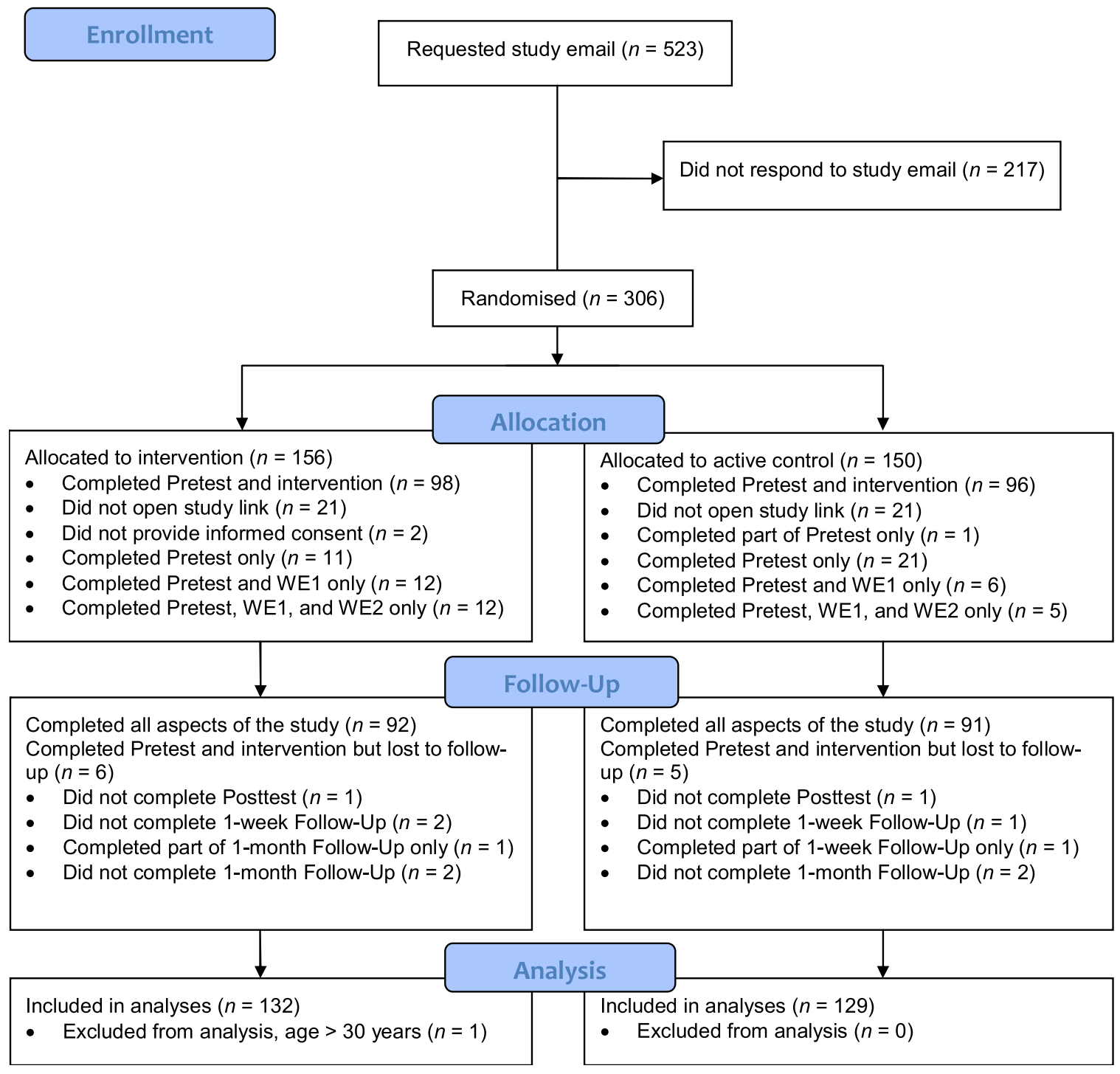

Fig. 1. Participant flow through the study. $W E=W r i t i n g$ Exercise. 
level) from 1 = strongly dislike to 5 = strongly like. Participants' scores are averaged, with higher scores showing greater functionality satisfaction. This subscale has demonstrated internal consistency and construct validity in female undergraduates (Franzoi \& Herzog, 1986; Franzoi \& Shields, 1984). In this study, Cronbach's alpha at Pretest, Posttest, 1-week Follow-Up, and 1-month Follow-Up was $.84, .90, .91$, and .91 , respectively.

\subsubsection{Body Appreciation Scale-2 (BAS-2; Tylka E Wood-Barcalow, 2015b)}

The BAS-2 comprises 10 items (e.g., "I appreciate the different and unique characteristics of my body") rated from $1=$ never to $5=$ always. Scores on the 10 items are averaged; higher scores reflect greater body appreciation. In U.S university and community women, the BAS-2 has demonstrated internal consistency, construct validity, and 20-day test-retest reliability (Tylka \& WoodBarcalow, 2015b). In this study, Cronbach's alpha at Pretest, Posttest, 1-week Follow-Up, and 1-month Follow-Up was .93, .96, .96 , and .96 , respectively.

\subsubsection{Body Complexity Questionnaire (BCQ; Harrison, 2006)}

Participants are instructed to list words describing their bodies as they think they actually are. They are given 10 spaces for their answer, but are told that they can use fewer or more spaces. Participants are given two minutes to complete their list. Participants' lists are scored based on the number of distinct body-aspects provided; for example, if a participant provides synonyms for the same body-aspect (e.g., thin and skinny) these are scored as one distinct body-aspect. Higher total numbers of distinct body-aspects reflect higher levels of body complexity. The first and sixth author independently scored all lists, with condition concealed (intra-class correlation coefficients $>.95$ for all time points). They then discussed any instances where total scores differed by three or more body-aspects until consensus was reached. The final data for body complexity concern the scores as determined after discussion, with an average taken for the number of body-aspects scored by the first and sixth author.

\subsubsection{Body-Self Integration Scale (BSI; Goldenberg E Shackelford, 2005)}

The BSI instructs participants to think about who they are, and then how much their physical body is part of who they are. Next, participants are asked to select one of seven pairs of circles that best represents the relationship between their self and their body. The pairs of circles increasingly overlap, with the first pair touching but non-overlapping and the seventh pair almost entirely overlapping. Responses are scored from 1 = first pair to 7 = last pair; higher scores reflect greater body-self integration. This format has been used to assess relations between other sets of concepts, such as the self and a significant other, and has demonstrated test-retest reliability and construct validity (Aron, Aron, \& Smollan, 1992).

\subsubsection{Body Satisfaction Visual Analogue Scales (VAS; Heinberg \& Thompson, 1995)}

VAS items were used to assess participants' current levels of physical appearance satisfaction and physical appearance dissatisfaction (reverse-scored) from $1=$ none to $100=$ extreme. They were interspersed with five filler items assessing mood. Scores on the two items were averaged; higher scores show greater state body satisfaction. These items have demonstrated internal reliability and 5-min test-retest reliability, and are sensitive to experimental manipulations (Alleva, Veldhuis, \& Martijn, 2016; Birkeland et al., 2005). In this study, Cronbach's alpha at Pre- and Post-Exposure was .73 and .68 , respectively.

\subsubsection{Demographic items}

Participants reported their age, weight and height (to calculate BMI), highest completed educational level, ethnicity, and sexual orientation.

\subsection{Materials}

\subsubsection{Intervention}

The functionality group completed the Expand Your Horizon programme (see Alleva, Martijn et al., 2015, for the full instructions). Participants are given a brief introduction to body functionality including a list of body functions categorised per domain - and why it is important. They are told that the programme will help them to focus more on their body functionality. Then the programme consists of three writing exercises, each focusing on two different domains of body functionality. Per exercise, participants are asked to describe the functions that their body can perform regarding the two domains, and to reflect on why they are personally meaningful. They also receive a link to the list of body functions, for inspiration.

The active control group completed a creativity training programme (Alleva, Martijn et al., 2015). The programme begins with an introduction to creativity and why it is important to foster creative skills (to improve overall well-being). Participants are told that the programme will help them to develop their creative skills by working on a series of fictional short stories. In three writing exercises, participants select a main character (not themselves), setting, and plot, and write a fictional short story using these aspects. In the second and third writing exercise, participants are asked to select a different main character, setting, and plot than in their previous exercise(s). They are told that the goal is not to finish their fictional short stories, but to focus on the process of creative writing.

For all writing exercises of both programmes, participants are asked to (a) keep writing once started, (b) try to write for at least $15 \mathrm{~min}$, and (c) re-read what they have written once finished. They are reminded not to worry about spelling or grammar, and that everyone is unique, so their writing will be, too.

\subsubsection{Media exposure}

Beauty-ideal media exposure comprised 21 advertisements. Thirteen advertisements each featured a thin, toned, and attractive female model, from at least the thighs upward. To disguise the focus of exposure, they were interspersed with eight productonly advertisements (Andrew, Tiggemann, \& Clark, 2015). This set of advertisements has significantly reduced state body satisfaction in pilot research with female undergraduates in our lab. Products-only exposure comprised the same eight product-only advertisements from the beauty-ideal exposure, and 13 additional product-only advertisements selected from our prior research with female undergraduates (Alleva et al., 2016) and from Andrew et al. (2015). In both beauty-ideal and products-only exposure, the products-only advertisements featured perfumes, watches, handbags, footwear, and cosmetics.

\subsection{Procedure}

This study was approved by the ethics committee at the University of the West of England. Participants were recruited via advertisements on campus, the university's online recruitment system, the Call For Participants website, social networking websites, and mailing lists (e.g., Body Gossip and Be Real: The Campaign for Body Confidence). Advertisements stated that we were testing two body image programmes, and that candidates must be women based in England, aged 18-30, with a good understanding of English, and a desire to improve how they feel about their body. 
Recruitment occurred from September 2016 to February 2017, by which time at least 180 participants had completed the study.

The study took place online and was managed by Maastricht University's online research system. Women interested in the study received an information sheet, stating that we were testing two body image programmes and that they would be randomised to one of the two. Note that participants were not given any information about the content of the programmes. If they agreed to participate, the first author added their e-mail address to the research system and indicated their randomly assigned condition, determined by a randomisation list (Graph Pad Software, 2012) with a 1:1 allocation ratio. The research system then sent the participants a link to Session 1 . Thereafter, all communication was managed by the research system alone.

At Session 1, participants first completed an electronic informed consent sheet, followed by the Pretest and first writing exercise. At Session 2, two days later, participants completed their second writing exercise. Two days afterward, they completed Session 3, comprising their final writing exercise, followed by the Posttest and demographic items. At Session 4, one week later, participants completed the first Follow-Up and then the media exposure. The research system randomly assigned participants to either the beauty-ideal or products-only exposure, with a 1:1 allocation ratio within both the functionality and control groups. Participants were told that the researchers were creating a well-being magazine for women in England and wanted their opinion about the kinds of advertisements they like. Next, they filled in the VAS and were exposed to the media imagery. Each advertisement appeared for 25s. To increase engagement and fit the cover story, participants completed two filler items concerning their opinions while viewing each advertisement (Andrew et al., 2015). After exposure, participants completed the VAS again, and another filler question.

Session 5 occurred three weeks later. Participants completed the second Follow-Up and received research credit or a $£ 10$ voucher. Participants in the control group could then choose to complete Expand Your Horizon (no further measures were given). Debriefing letters were sent after data collection was complete. Note that all questionnaires were administered at all time points, with the exception of the demographic items (Pretest only) and the VAS (Pre- and Post-Exposure only).

The research system sent reminder e-mails to participants one day before each session. On the morning of each session, participants received a personal link. If participants did not complete a session on the assigned day, they received a reminder one day, and then two days afterward. If participants had still not completed the session on the third day, they were notified that they were ineligible to complete the remainder of the study.

\section{Results}

\subsection{Descriptive statistics and preparation of the dataset}

Participants' Pretest, Posttest, 1-week Follow-Up, and 1-month Follow-Up scores are shown in Table 1 (see Supplementary Materials for the correlations between these scores). A series of $t$-tests showed that there were no significant differences between groups on any of the Pretest measures, Age $\left(M_{\text {functionality }}=22.89, S D=3.67\right.$; $\left.M_{\text {control }}=22.68, S D=3.83\right)$, or BMI $\left(M_{\text {functionality }}=23.66, S D=5.89\right.$; $\left.M_{\text {control }}=23.43, S D=5.07\right)$, all $p s>.05$.

Inspection of missing data revealed that $26.8 \%$ of participants did not continue the study after completing the Pretest. At 1-week and 1-month Follow-Up, attrition increased to $28.0 \%$ and $29.9 \%$ of the original sample, respectively. One reason for the attrition rate concerns a technical error that occurred during testing (see Discussion). Conducted $t$-tests showed that Pretest scores did not differ between participants who had completed all measures and those who had dropped out ( $p s>.05$ ). In addition to those who dropped out eventually, $5.0 \%$ of the participants with otherwise complete cases had missing data on all body complexity measurements, and a further $3.4 \%$ missed one or more time points. In these cases, participants had completed the BCQ incorrectly (e.g., they simply listed body parts). Given these missing data, multiple imputation was applied to complete the dataset using the packages 'mitml' (Grund, Robitzsch, \& Luedtke, 2017) and 'pan' (Zhao \& Schafer, 2016) for multiple imputation of multilevel data in R(R Core Team, 2015). We used 100 imputed datasets (Graham, Olchowski, \& Gilreath, 2007). Statistical models for data imputation used all variables included

Table 1

Pretest, Posttest, and Follow-Up scores for the functionality and control groups.

\begin{tabular}{|c|c|c|c|c|c|c|c|c|c|c|}
\hline & \multicolumn{5}{|c|}{ Functionality group } & \multicolumn{5}{|c|}{ Control group } \\
\hline & $n$ & $M$ & $S D$ & $\min$ & $\max$ & $n$ & $M$ & $S D$ & $\min$ & $\max$ \\
\hline \multicolumn{11}{|l|}{ Appearance satisfaction } \\
\hline Pretest & 132 & 2.75 & 0.60 & 1.44 & 4.33 & 129 & 2.89 & 0.69 & 1.33 & 4.89 \\
\hline Posttest & 96 & 3.12 & 0.78 & 1.33 & 4.89 & 95 & 2.98 & 0.70 & 1.11 & 4.78 \\
\hline 1-week Follow-Up & 94 & 3.13 & 0.77 & 1.44 & 5.00 & 94 & 3.05 & 0.75 & 1.22 & 4.78 \\
\hline 1-month Follow-Up & 92 & 3.16 & 0.82 & 1.00 & 4.78 & 91 & 3.09 & 0.77 & 1.00 & 4.78 \\
\hline \multicolumn{11}{|l|}{ Functionality satisfaction } \\
\hline Pretest & 132 & 2.83 & 0.73 & 1.00 & 4.78 & 129 & 2.94 & 0.75 & 1.00 & 4.78 \\
\hline Posttest & 96 & 3.23 & 0.83 & 1.00 & 5.00 & 95 & 3.02 & 0.81 & 1.00 & 4.78 \\
\hline 1-week Follow-Up & 94 & 3.19 & 0.83 & 1.00 & 5.00 & 94 & 3.00 & 0.85 & 1.00 & 5.00 \\
\hline 1-month Follow-Up & 92 & 3.26 & 0.84 & 1.00 & 5.00 & 91 & 3.08 & 0.81 & 1.00 & 4.89 \\
\hline \multicolumn{11}{|l|}{ Body appreciation } \\
\hline Pretest & 132 & 2.82 & 0.75 & 1.10 & 5.00 & 129 & 2.90 & 0.81 & 1.40 & 5.00 \\
\hline Posttest & 96 & 3.25 & 0.89 & 1.00 & 5.00 & 95 & 3.04 & 0.87 & 1.00 & 5.00 \\
\hline 1-week Follow-Up & 94 & 3.24 & 0.89 & 1.00 & 5.00 & 94 & 3.06 & 0.90 & 1.00 & 5.00 \\
\hline 1-month Follow-Up & 92 & 3.30 & 0.95 & 1.00 & 5.00 & 91 & 3.16 & 0.92 & 1.00 & 5.00 \\
\hline \multicolumn{11}{|l|}{ Body complexity } \\
\hline Pretest & 119 & 5.16 & 2.43 & 1.00 & 11.50 & 118 & 5.32 & 2.76 & 1.00 & 12.50 \\
\hline Posttest & 85 & 6.62 & 2.92 & 1.00 & 16.00 & 89 & 5.36 & 2.92 & 0.50 & 13.00 \\
\hline 1-week Follow-Up & 82 & 6.53 & 2.95 & 1.00 & 16.00 & 87 & 5.64 & 2.86 & 1.00 & 15.00 \\
\hline 1-month Follow-Up & 82 & 6.58 & 2.71 & 1.00 & 16.00 & 85 & 6.20 & 2.51 & 1.00 & 13.00 \\
\hline \multicolumn{11}{|l|}{ Body-self integration } \\
\hline Pretest & 132 & 3.76 & 1.54 & 1.00 & 7.00 & 129 & 3.81 & 1.59 & 1.00 & 7.00 \\
\hline Posttest & 96 & 4.28 & 1.70 & 1.00 & 7.00 & 95 & 4.21 & 1.54 & 1.00 & 7.00 \\
\hline 1-week Follow-Up & 94 & 4.24 & 1.63 & 1.00 & 7.00 & 93 & 4.29 & 1.61 & 1.00 & 7.00 \\
\hline 1-month Follow-Up & 92 & 4.30 & 1.69 & 1.00 & 7.00 & 91 & 4.42 & 1.64 & 1.00 & 7.00 \\
\hline
\end{tabular}


Table 2

Results of the final multilevel models testing the effect of Group on body image over time

\begin{tabular}{|c|c|c|c|c|c|c|c|c|c|}
\hline & \multicolumn{3}{|c|}{ Appearance satisfaction } & \multicolumn{3}{|c|}{ Functionality satisfaction } & \multicolumn{3}{|c|}{ Body appreciation } \\
\hline & $B$ & 95\% C.I. & & $B$ & 95\% C.I. & & $B$ & 95\% C.I. & \\
\hline Fixed Effects & & & & & & & & & \\
\hline Intercept & $2.95^{* * *}$ & 2.87 & 3.05 & $2.98^{* * *}$ & 2.88 & 3.08 & $3.07^{* * *}$ & 2.97 & 3.17 \\
\hline Time & $0.00^{*}$ & 0.00 & 0.01 & 0.00 & 0.00 & 0.00 & $0.00^{*}$ & 0.00 & 0.01 \\
\hline Pretest & $0.94^{* * *}$ & 0.85 & 1.04 & $0.87^{* * *}$ & 0.78 & 0.96 & $0.96^{* * *}$ & 0.86 & 1.05 \\
\hline Functionality Group & $0.19^{* *}$ & 0.06 & 0.32 & $0.22^{* *}$ & 0.08 & 0.37 & $0.16^{*}$ & 0.02 & 0.30 \\
\hline Time $\times$ Functionality Group & -0.00 & -0.01 & 0.00 & 0.00 & 0.00 & 0.00 & 0.00 & -0.01 & 0.00 \\
\hline Variance & Baseline & Final & Baseline & Final & Baseline & Final & & & \\
\hline Individual & 0.167 & 0.160 & 0.211 & 0.199 & 0.213 & 0.208 & & & \\
\hline Residual & 0.067 & 0.067 & 0.084 & 0.084 & 0.069 & 0.069 & & & \\
\hline
\end{tabular}

in the analyses, except for body complexity and body-self integration, which were excluded as their relationship with the body image outcomes has not yet been supported by an extensive body of research.

\subsection{Checking the writing exercise responses}

The first author checked the content of participants' writing exercise responses, all of which matched the instructions of their group. There were no group differences concerning the average number of words written, per writing exercise, across the interventions $\left(M_{\text {functionality }}=382.94, S D=174.24 ; M_{\text {control }}=352.30\right.$, $S D=136.43), t(227)=1.47, p=.144$. The research system recorded how much time participants spent on the page displaying the text entry box for the writing exercise responses, giving an indication of how much time participants spent on the writing exercises. There were no group differences concerning the average number of minutes that participants spent on this page, per writing exercise, across the interventions $\left(M_{\text {functionality }}=30.90, S D=55.64\right.$; $\left.M_{\text {control }}=48.85, S D=130.04\right), t(139.62)=-1.33, p=.187$.

\subsection{Testing the effects of the intervention}

We used longitudinal multilevel models to assess the effect of Group on each body image outcome (i.e., appearance satisfaction, functionality satisfaction, body appreciation) across Time. Multilevel modelling was chosen as it poses less stringent assumptions on the data than, for example, repeated measures ANOVA. The former does not require sphericity and a balanced design, and, of particular relevance to the current study, it allows for flexible modelling of Time effects: We were able to accurately model the spacing between the different time points, investigate whether change over time occurred in a linear fashion, and establish whether change over time varied between participants (see Hayes, 2006, for a primer on multilevel modelling). Analyses were conducted in $R$ ( $R$ Core Team, 2015) using the package 'lme4' (Bates, Mächler, Bolker, \& Walker, 2015).

Given that the intervals between different time points varied, Time was included as a continuous predictor in the model as the number of days of a given measurement since Posttest, with Posttest included at '0.' Pretest was included in the model as a (grand-mean centred) covariate. Before arriving at the final model, several models were compared to ensure that the final model specification was appropriate for the data. For brevity, for the intermediate models, only the main conclusions are reported; for the final model for each outcome, the complete results are reported (see Table 2). To establish how Time should be included in the model, we first tested whether the relationship between Time and the outcomes varied between participants. To do so, we compared a random intercepts model, including Time as a fixed effect, with a model also including random slopes for Time. As we used multiple imputation, we could not directly compare the two models using a single likelihood ratio test; instead, we used the $D_{L}$ method proposed by Meng and Rubin (1992) to combine the model results of all imputed datasets. The $D_{L}$ method produces a test-statistic which is approximated by an $F$-distribution, where a significant $F$-value indicates significant improvement of the random slopes model over the random intercepts model. The $F$ tests indicated that including random slopes did not lead to a significant improvement over the random intercepts model for any of the outcomes (all ps >.05). These results indicate that the relationship between Time and body image did not significantly vary between participants. As such, we proceeded with a model only including random intercepts. Next, we tested whether the relationship between Time and the outcomes was linear or quadratic by including an additional predictor of Time-squared in the model. This additional term was not significant for any of the outcomes ( $p s>.05$ ), leading us to proceed to modelling Time as a linear relationship with the outcomes.

The coefficients for the final model for each outcome are reported in Table 2. Group was a significant predictor for each of the outcomes. The parameter estimates demonstrate that, compared to controls, participants in the functionality group experienced improved appearance satisfaction, functionality satisfaction, and body appreciation. The absence of a significant Group $\times$ Time interaction effect showed that the differences in body image between Groups at Posttest were maintained at 1-week and 1-month Follow-Up. Note that, for appearance satisfaction and body appreciation only, we also observed a significant, positive effect of Time, suggesting that all participants increased their ratings over time. However, the magnitude of this effect (with coefficients $B=0.003$ and $B=0.004$, respectively) is negligible.

Table 2 also shows the variance estimates observed for each outcome, both for the final model and for a baseline model excluding Group and Group $\times$ Time. Comparing the variance estimates of the baseline with the final models allows for the calculation of the percentage reduction in variance observed as a function of adding Group to the model (see e.g., Peugh, 2010). This approach revealed a respective $4.2 \%, 5.3 \%$, and $1.9 \%$ reduction in variance on the individual level for appearance satisfaction, functionality satisfaction, and body appreciation.

\subsection{Testing the potential mediators of the intervention effects}

We conducted a mediation analysis to test whether the relationship between Group and the outcomes was mediated by body complexity and/or body-self integration. Given the longitudinal 
Table 3

Model fit indices for all structural equation models.

\begin{tabular}{|c|c|c|c|c|c|c|c|c|c|c|c|c|}
\hline & \multicolumn{4}{|c|}{ Appearance satisfaction } & \multicolumn{4}{|c|}{ Functionality satisfaction } & \multicolumn{4}{|c|}{ Body appreciation } \\
\hline & RSMEA & SRMR & CFI & AIC & RSMEA & SRMR & CFI & AIC & RSMEA & SRMR & CFI & AIC \\
\hline 1 & 0.077 & 0.060 & 0.997 & 2875.766 & 0.082 & 0.062 & 0.997 & 2990.848 & 0.000 & 0.041 & 1.000 & 2944.289 \\
\hline 2 & 0.044 & 0.055 & 0.998 & 2873.106 & 0.039 & 0.065 & 0.998 & 2987.611 & 0.000 & 0.044 & 1.000 & 2941.009 \\
\hline 3 & 0.064 & 0.062 & 0.996 & 2874.519 & 0.037 & 0.056 & 0.999 & 2987.532 & 0.000 & 0.031 & 1.000 & 2942.025 \\
\hline 4 & 0.000 & 0.053 & 1.000 & 2869.411 & 0.020 & 0.059 & 0.999 & 2985.015 & 0.000 & 0.026 & 1.000 & 2938.898 \\
\hline
\end{tabular}

Table 4

Body complexity, body-self integration, and state body satisfaction scores for the beauty-ideal vs. products-only Media Exposure groups.

\begin{tabular}{|c|c|c|c|c|c|c|c|c|c|c|}
\hline & \multicolumn{5}{|c|}{ Beauty-Ideal Exposure } & \multicolumn{5}{|c|}{ Products-Only Exposure } \\
\hline & $n$ & $M$ & $S D$ & $\min$ & $\max$ & $n$ & $M$ & $S D$ & $\min$ & $\max$ \\
\hline Body complexity 1 -week Follow-Up & 82 & 6.23 & 3.04 & 1.00 & 16.00 & 87 & 5.93 & 2.83 & 1.00 & 15.00 \\
\hline Body-self integration 1-week Follow-Up & 94 & 4.33 & 1.60 & 1.00 & 7.00 & 93 & 4.20 & 1.64 & 1.00 & 7.00 \\
\hline Pre-Exposure body satisfaction & 94 & 47.78 & 20.58 & 3.50 & 92.00 & 93 & 49.59 & 22.72 & 3.00 & 92.00 \\
\hline Post-Exposure body satisfaction & 94 & 44.39 & 20.57 & 0.50 & 87.50 & 93 & 53.02 & 22.82 & 8.00 & 100.00 \\
\hline
\end{tabular}

nature of the data, we first investigated whether any mediation was cross-sectional or time-lagged, and whether any time-lagged relationship between mediator and outcome was in the expected direction. For each outcome, we specified four structural equation models: (1) all time-lagged paths (between adjacent time points) between mediator and outcome and vice versa, including cross-sectional correlations; (2) only time-lagged paths from the mediator at time-point $(t-1)$ to the outcome at time-point $t$; (3) only time-lagged paths from the outcome at time-point $(t-1)$ to the mediator at time-point $t$; and (4) only cross-sectional paths from mediator to outcome. In each model, we further allowed for timelagged correlations on the same measure. We compared model fit indices of each of these models to see which model was most appropriate for the data. Structural equation models were fitted using the 'lavaan' package in R (Rosseel, 2012).

Model fit indices for all structural equation models are reported in Table 3. Note that AIC is a relative model fit measure, and that a lower value indicates a better model. For all outcomes, the crosssectional mediation paths (Model 4) demonstrated the best model fit. As such, we proceeded with testing this mediation.

For the mediation analyses, we followed MacKinnon, Lockwood, Hoffman, West, and Sheets (2002), who recommended testing the joint significance of (a) the mediator regressed on the independent variable, and (b) the outcome regressed on the mediator in the model where the independent variable is also included. To test these paths, we specified longitudinal multilevel models in line with our first hypothesis. That is, a random intercepts model including Time as a linear predictor, and the Pretest measure for the relevant outcome - and in this case also for the relevant mediator - included as grand-mean centred covariates.

Results of the first path (a) indicated that Group significantly predicted body complexity $\left(B_{\text {Functionality }}=0.91, p=.006,95 \%\right.$ C.I. $=[0.25,1.56])$, with the parameter estimate showing that participants in the functionality group experienced significantly higher body complexity. Group did not significantly predict body-self integration ( $B_{\text {Functionality }}=-0.10, p=.594,95 \%$ C.I. $=[-0.48,0.28]$ ), leading us to proceed with path (b) for body complexity only. Results of path (b) showed that body complexity did not significantly predict any of the outcomes (appearance satisfaction: $B_{\text {Complexity }}=0.01, p=.276,95 \%$ C.I. $=[-0.01,0.02]$; functionality satisfaction: $B_{\text {Complexity }}=0.01, p=.508,95 \%$ C.I. $=[-0.01,0.02]$; body appreciation: $B_{\text {Complexity }}=0.01, p=.104,95 \%$ C.I. $=[-0.00,0.03]$ ). Thus, although participants in the functionality group experienced higher body complexity, we found no evidence for mediation of the intervention effects.

\subsection{Testing the buffering effects of body complexity and body-self} integration

We tested whether media exposure (beauty-ideal $v s$. productsonly) affected state body satisfaction, and whether an effect of media exposure was moderated by body complexity and/or bodyself integration. For completeness, we also tested whether the effect of media exposure on state body satisfaction interacted with Group. Descriptive statistics are reported in Table 4. Conducted $t$ tests showed that there was no significant difference in state body satisfaction at pre-exposure between participants who received beauty-ideal $v s$. products-only exposure $(p>.05)$.

At the time of exposure, $28.0 \%$ of the initial sample had dropped out and thus no data were available concerning their pre- or postexposure state body satisfaction. Therefore, these cases were not considered for this set of analyses, leading to $n=187$. From this sample, $9.6 \%$ of individuals did not have data available on body complexity. Multiple imputation was applied to complete the dataset using the 'mice' package in R (van Buuren \& Groothuis-Oudshoorn, 2011), and we set the method to 100 imputations (Graham et al., 2007). The statistical model used for imputation included all body complexity and body-self integration measures.

The effect of media exposure on state body satisfaction, its interaction with Group, and the possible moderation of body complexity and body-self integration on the effect of media exposure on state body satisfaction was investigated using two linear regression models. In the first model, we tested the main effects of media exposure, Group, body complexity, and body-self integration on state body satisfaction. In the second model, we included the interaction of media exposure with Group, and the interaction of media exposure with body complexity and body-self integration. Results are reported in Table 5.

The analyses revealed a main effect of media exposure, with exposure to beauty-ideal imagery leading to lower state body satisfaction, as would be expected (Grabe et al., 2008). The interaction between media exposure and Group was nonsignificant, showing that the impact of media exposure on state body satisfaction did not differ for participants in the functionality $v s$. control groups. Unexpectedly, there was no evidence for the moderation of this relationship by body complexity or body-self integration, although there was a trend for the interaction effect including body complexity. 
Table 5

Linear regression results testing the effect of Media Exposure on state body satisfaction and the moderation of this effect by Body Complexity and Body-Self Integration.

\begin{tabular}{|c|c|c|c|c|c|c|}
\hline & \multicolumn{3}{|c|}{ Main effects } & \multicolumn{3}{|c|}{ Including Moderations } \\
\hline & $B$ & 95\% C.I. & & $B$ & 95\% C.I. & \\
\hline Intercept & $17.05^{* *}$ & 10.79 & 23.32 & $16.94^{* *}$ & 10.24 & 23.64 \\
\hline Functionality Group & -0.76 & -5.06 & 3.53 & -0.15 & -6.15 & 5.85 \\
\hline Beauty-Ideal Exposure & $-7.32^{* *}$ & -11.58 & -3.06 & $-7.04^{*}$ & -13.07 & -1.00 \\
\hline Body Complexity 1-Week Follow-Up & -0.16 & -0.93 & 0.62 & 0.47 & -0.64 & 1.58 \\
\hline Body-Self Integration 1-Week Follow-Up & 0.53 & -0.87 & 1.92 & 1.45 & -0.44 & 3.34 \\
\hline Pre-Exposure Body Satisfaction & $0.73^{* *}$ & 0.63 & 0.84 & $0.73^{* *}$ & 0.63 & 0.84 \\
\hline Functionality Group $\times$ Beauty-Ideal Exposure & & & & -0.60 & -9.16 & 7.95 \\
\hline Beauty-Ideal Exposure $\times$ Body Complexity & & & & $-1.34^{\dagger}$ & -2.89 & 0.21 \\
\hline Beauty-Ideal Exposure $\times$ Body-Self Integration & & & & -2.18 & -4.83 & 0.46 \\
\hline
\end{tabular}

Note: Main effects model $\mathrm{R}^{2}=.57$ (adj. $\mathrm{R}^{2}=.56$ ); moderations model $\mathrm{R}^{2}=.58$ (adj. $\mathrm{R}^{2}=.56$ ).

${ }^{*} p<.05$.

** $p<.001$.

$p<.10$.

\section{Discussion}

This study investigated whether and how focusing on body functionality leads to improvements in body image. The findings showed that women in the Expand Your Horizon programme, who focused on their body functionality, experienced improved trait appearance satisfaction, functionality satisfaction, and body appreciation at Posttest, and these effects persisted to both 1-week and 1-month Follow-Up. In addition, two constructs - body complexity and body-self integration - were investigated as potential mechanisms that could explain the ways in which focusing on body functionality causes improvements in body image. Focusing on body functionality increased levels of body complexity at Posttest and at both 1-week and 1-month Follow-Up, but neither construct proved to be an underlying mechanism of intervention effects. Further, exposure to beauty-ideal media imagery at 1-week Follow-Up led to reductions in women's state body satisfaction, but neither body complexity nor body-self integration nor taking part in the intervention programme buffered these effects.

This study extended prior experimental research (Alleva et al., 2014; Alleva, Martijn et al., 2015) by replicating the beneficial impact of focusing on body functionality in an additional large sample of women, and by demonstrating that the effects of Expand Your Horizon persist one month after completing the programme. These findings are noteworthy, considering the brevity of the programme (i.e., taking $45 \mathrm{~min}$ to complete across one week) and that we recruited women who were unhappy with their body. Although the present participants were not formally screened for having a negative body image as in Alleva, Martijn et al. (2015), initial levels of trait appearance satisfaction, functionality satisfaction, and body appreciation were comparable across samples. The current findings provide additional support showing that focusing on body functionality is a fruitful approach for improving women's body image. Further, given that the programme is easy and affordable to disseminate (i.e., hosted online, without an interventionist), it could be disseminated to wider populations of women who may benefit from it.

It is also noteworthy that the programme improved aspects of positive body image (trait body appreciation) and focused on women's strengths concerning their own body. In this way, Expand Your Horizon fits within a broader framework of positive body image-based approaches to improving body image, and could be useful for interventionists who wish to improve aspects of positive body image in addition to reducing aspects of negative body image - a strategy which has been proposed to lead to a healthier body image overall (Tylka \& Wood-Barcalow, 2015a). It will also be helpful as a complement to extant programmes and could ensure that both physical appearance and body functionality are addressed to comprehensively improve body image. Future research is needed to investigate the impact of the approach in other target groups and intersecting social identities, such as in adolescents, other genders, individuals from different cultural backgrounds and professions, and those who have physical conditions that may limit their functional capacities (see Alleva et al., 2017, for a discussion). It will also be interesting to explore other ways in which a functionality-focus can be practiced, for example by actively engaging in embodying activities (e.g., Cook-Cottone et al., 2013; Halliwell, 2015; Mahlo \& Tiggemann, 2016; Menzel \& Levine, 2011; Swami, 2017; Swami \& Tovée, 2009; Tiggemann et al., 2014). This knowledge could be used to develop more elaborate functionality-based programmes.

Body complexity did not mediate the impact of focusing on body functionality on women's body image. Yet, the fact that women in the Expand Your Horizon programme did experience increased body complexity supports the idea that focusing on body functionality can help women to recognise and appreciate the greater complexity of their body-concept. That is, that their body-concept can comprise aspects that are not limited to appearance or to any one particular domain of body functionality or specific functions. It is promising that after just three writing exercises, women in the Expand Your Horizon programme developed a more complex body-concept. It is also possible that the present improvements in body complexity, as measured by the BCQ, merely reflect training effects of the Expand Your Horizon writing exercises. However, the fact that improvements in body complexity were present at 1-week and 1-month Follow-Up suggests that participants were not simply repeating what they had written during the programme, but had learned to conceptualise their body-concept in a more complex way. These findings are promising because they show that, although there are experiences that can limit the body-concept (Harrison, 2006), there are also experiences that can expand the body-concept.

Why did improvements in body complexity not translate to improvements in body image, or to buffering effects in the face of beauty-ideal media imagery? Koch and Shepperd (2004) stated that prospective study designs are the most appropriate for testing the predictions of Linville's (1985, 1987); theorising on self-complexity. This is because the benefits of self-complexity concerning mitigating the impact of negative experiences can only be identified across time, when individuals have had sufficient opportunity to experience and adapt to such experiences. That is, self-complexity may not confer any immediate benefits at one particular time point, or in the short term, yet its impact may in fact be seen in the longer-term. If this is the case, it could be that our 1-month Follow-Up was not long enough to identify mediating effects, and longer-term assessments should be included in future research. Indeed, other mediational research has shown that the timing of assessments may be crucial. For example, Slater and 
Tiggemann (2012) showed that sports participation was inversely correlated with self-objectification in adolescent girls, but this relationship only emerged across one year, and sports participation and self-objectification were not correlated at baseline. Of course, the fact that Expand Your Horizon participants experienced improvements in body image from Posttest onwards suggests that other mechanisms could be playing a role on the shorter term.

Another possibility concerns the valence of body-aspects that women identify. In the self-complexity literature, some scholars have recommended investigating self-complexity in terms of positive and negative self-complexity: the number of distinct positive and negative self-aspects comprising the self-concept, respectively (see Koch \& Shepperd, 2004, for a review). For example, Morgan and Janoff-Bulman (1994) found that overall self-complexity was not related to coping with traumatic experiences, but people with high levels of positive self-complexity coped with traumatic experiences better than individuals with high levels of negative self-complexity. Note that Linville conceptualised self-complexity as a unitary, structural aspect of the self-concept, without regard for valence. Yet, investigating body complexity as differentiated into positive and negative body complexity could be worthwhile. As has been done for self-complexity measures (Koch \& Shepperd, 2004), this would require adapting the BCQ to objectively assess participants' own evaluations of their body-aspects (e.g., the word 'fat' may be used in a negative, neutral, or positive way; Saguy \& Ward, 2011).

It is also interesting that focusing on body functionality did not increase women's body-self integration. It could be that integrating the body and self might require more time and practice, especially for women with a more negative body image who have become accustomed to seeing their body as a "separate, 'other' territory" (Piran, 2016, p. 48), a perspective that likely developed over a long period of time. Another reason for these findings concerns how body-self integration was operationalised, using the BSI (Goldenberg \& Shackelford, 2005). The BSI instructions are phrased in a neutral manner, as participants are only asked to identify the pair of circles that best represents the relationship between their self- and body-concepts. As such, these instructions could enable individuals to interpret the BSI in either a negative or positive manner. For example, selecting the pair of circles that are entirely overlapping could signal a positive sense of connection between the body and self (Piran, 2016), but also an over-identification with one's body or physical appearance (e.g., "I am my appearance"). Note, however, that BSI scores positively correlated with other aspects of body image (e.g., body appreciation; Supplementary Materials). Nevertheless, future research could include alternative measures to capture body-self integration, such as the emerging Experience of Embodiment Scale (Teall \& Piran, 2015), and could complement quantitative assessments with qualitative ones (e.g., interviewing participants to explore self-perceived mechanisms of change). The Experience of Embodiment Scale has not yet been formally published, and was therefore not available when this study was planned.

Last, though not the primary focus of this study, it is interesting that we did not find any differences between women in the Expand Your Horizon or active control programme concerning the impact at 1-week Follow-Up of beauty-ideal media exposure on state body satisfaction. These findings align with a recent experiment by Mulgrew et al. (2017), in which writing 10 positive statements about one's body functionality did not protect women from experiencing decreased state appearance and functionality satisfaction after beauty-ideal media exposure immediately afterward. In contrast, in a prior experiment by Alleva et al. (2016), female undergraduates completed a one-session variant of Expand Your Horizon or an active control exercise, and were then immediately exposed to beauty-ideal media imagery. Relative to control, participants who had described their body functionality expe- rienced greater functionality satisfaction and body appreciation Post-Exposure, leading Alleva et al. (2016) to conclude that focusing on body functionality could protect women from some of the harmful effects of beauty-ideal media imagery on their body image.

It is currently unclear why the present findings, and those of Mulgrew et al. (2017), contrast those of Alleva et al. (2016). In the present study, state body satisfaction was assessed as relating to appearance satisfaction only, to reduce participant burden and the likelihood that they would guess the true aim of the exposure. Interestingly, Alleva et al. did not find any protective effects for appearance satisfaction, either (cf. Mulgrew et al., 2017). Future research should therefore incorporate indices of various aspects of state body image. Another potential difference between the present study and Alleva et al. concerns the timing of the manipulations. Namely, Alleva et al.'s participants completed the functionality writing exercise immediately prior to media exposure, whereas in the present study media exposure occurred one week after the last writing exercise. For protective effects to occur, it may be important for individuals to actively reflect on their body functionality immediately before exposure to beauty-ideal imagery. This would not explain, however, why Mulgrew et al. (2017) did not find any protective benefits of the functionality exercise that did occur immediately before media exposure. Future research is needed to investigate how to tailor the functionality-based approach (e.g., in terms of timing, duration, nature of the task) to more effectively protect women from the potential harmful impact of beauty-ideal media exposure.

\subsection{Strengths and limitations of the study}

One key strength of this study is that it adopted a randomisedcontrolled design, which is important for advancing the field of (positive) body image more broadly as it can help to answer questions of causality (Halliwell, 2015). In addition, the study included a 1-month follow-up measurement and an active rather than passive control group, both of which are comparatively uncommon in body image intervention research (Alleva, Sheeran et al., 2015). The study comprised a large sample of women from a different geographical region than prior research on the Expand Your Horizon programme (Alleva et al., 2014; Alleva, Martijn et al., 2015). We also tested potential mechanisms of the functionality-based approach within the randomised-controlled design and across time. Investigating potential mechanisms of body image improvement can help us to achieve a better understanding of how body image is shaped and how it can be more effectively improved. Last, the present research investigated not only the content of the body-concept, but also its structural properties, which may also play a role in shaping body image.

In addition to the potential limitations already discussed, one drawback of this study concerns the attrition rate, where $26.8 \%$ of participants dropped out after Pretest. This attrition rate contrasts Alleva, Martijn et al. (2015), where only three participants dropped out at this point. One likely reason for this attrition rate concerns a technical error that occurred, whereby emails from the research system were blocked from Microsoft accounts without the researchers' knowledge. As a result, a large number of participants did not receive their study emails and had been automatically excluded from the study by the research system. It is important to note, however, that the overall number of dropouts did not differ by group, Pretest scores for dropouts did not differ from those who remained in the study, and this error likely affected both groups equally. Also, the present attrition rates are still lower than other online body image programmes (e.g., Albertson, Neff, \& DillSchackleford, 2014) and, more broadly, online interventions tend to have much higher attrition rates than in-person interventions (Eysenbach, 2005). Another drawback of this research and other 
online interventions is the inability to know exactly what participants were doing while engaging with the programme. Namely, although the research system recorded the amount of time that participants spent on the screen containing the text entry box for the writing exercises, this time provides only a rough estimate of the amount of time that participants actually spent on the writing exercises. Note, however, that in checking the content of participants' responses to the writing exercises, we did not come across any responses that indicated that participants did not make a serious attempt at completing the writing exercises.

An additional limitation of this study is that we did not assess participants' expectations about their assigned programme at Pretest. It could be that participants in the active control group were less convinced of the usefulness of the programme, and that improvements in the Expand Your Horizon participants were in part caused by demand characteristics. Relatedly, at the end of the 1-month Follow-Up, participants in the active control group were told that they could complete the "other body image programme," if desired. They were not given any information about the content of the programme, nor were they aware that they had been in the active control group as debriefing occurred only at the end of data collection. Surprisingly, of the 91 participants in the active control group who completed the 1-month Follow-Up, just six agreed to receive the "other" programme. This low number suggests that participants may not have been satisfied with the control programme and therefore did not have high expectations for the "other" programme. Alternatively, it could be that participants in the active control group did not agree to complete the "other" programme because they had already experienced some benefits from completing the study (e.g., reflecting on their body image via the questionnaires), or because they had already sought support elsewhere. To address these issues, future research could include a second active control programme that more closely concerns body image, and could assess participants' expectations at Pretest as well as whether they have sought additional support and why they would or would not sign up for any "other" programmes offered.

Another limitation to this study is that we measured functional aspects of body image using the Physical Condition Subscale of the BES, which assesses body functionality as related to internal processes and physical capacities only, and concerns evaluations of body functionality. Future research should assess body functionality more holistically and assess appreciation of body functionality, which is a more inclusive concept and in line with conceptualisations of positive body image more broadly (Webb et al., 2015; Tylka \& Wood-Barcalow, 2015a). The recently-developed Functionality Appreciation Scale (FAS; Alleva et al., 2017) will be helpful in this regard. Last, our sample was relatively homogeneous concerning participant demographics and concerned women who wanted to improve their body image; research in more diverse samples and in universal samples is needed.

\subsection{Conclusions}

This study advanced the prior literature by showing that focusing on body functionality improved body image in an additional large sample of women who were unhappy with their body, and these improvements lasted one month after completion of the Expand Your Horizon programme. These findings provide additional support for the benefit of focusing on body functionality, and there are numerous promising directions for future research. This study also explored body complexity and body-self integration as potential mechanisms in the relation between focusing on body functionality and improvements in body image. While neither of these constructs proved to be underlying mechanisms of the approach and did not buffer the impact of beauty-ideal media exposure, the present research did show that focusing on body functionality can enhance women's body complexity. It is hoped that future research will continue to investigate the potential mechanisms of the functionality-based approach, as well as those underlying other strategies for improving body image.

\section{Acknowledgements}

The contribution of Jessica M. Alleva was supported by NWO grant 446-15-011: Handsome is as handsome does: Investigating body functionality and novel mechanisms of body image improvement, awarded to Jessica M. Alleva. The authors would like to thank Michiel Vestjens for programming the online intervention for this study and for managing technical issues. Last, the authors would also like to thank Body Gossip and Be Real: The Campaign for Body Confidence for their help with participant recruitment.

\section{Appendix A. Supplementary data}

Supplementary data associated with this article can be found, in the online version, at https://doi.org/10.1016/j.bodyim.2018.02. 009.

\section{References}

Albertson, E. R., Neff, K. D., \& Dill-Schackleford, K. E. (2014). Self-compassion and body dissatisfaction in women: A randomised controlled trial of a brief meditation intervention. Mindfulness, 6, 444-454. http://dx.doi.org/10.1007/ s12671-014-0277-3

Alleva, J. M., Martijn, C., Jansen, A., \& Nederkoorn, C. (2014). Body language: Affecting body language by describing the body in functionality terms. Psychology of Women Quarterly, 38, 181-196. http://dx.doi.org/10.1177/ 0361684313507897

Alleva, J. M., Veldhuis, J., \& Martijn, C. (2016). A pilot study investigating whether focusing on body functionality can protect women from the potential negative effects of viewing thin-ideal media images. Body Image, 17, 10-13. http://dx. doi.org/10.1016/j.bodyim.2016.01.007

Alleva, J. M., Tylka, T. L., \& Kroon Van Diest, A. M. (2017). The Functionality Appreciation Scale (FAS): Development and psychometric evaluation in U.S. community women and men. Body Image, 23, 28-44. http://dx.doi.org/10. 1016/j.bodyim.2017.07.008

Alleva, J. M., Martijn, C., Van Breukelen, G. J. P., Jansen, A., \& Karos, K. (2015). Expand Your Horizon: A programme that improves body image and reduces self-objectification by training women to focus on body functionality. Body Image, 15, 81-89. http://dx.doi.org/10.1016/j.bodyim.2015.07.001

Alleva, J. M., Sheeran, P., Webb, T. L., Martijn, C., \& Miles, E. (2015). A meta-analytic review of stand-alone interventions to improve body image. PLoS One, 10, e0139177. http://dx.doi.org/10.1371/journal.pone.0139177

Andrew, R., Tiggemann, M., \& Clark, L. (2015). The protective role of body appreciation against media-induced body dissatisfaction. Body Image, 15 98-104. http://dx.doi.org/10.1016/j.bodyim.2015.07.005

Aron, A., Aron, E. N., \& Smollan, D. (1992). Inclusion of Other in the Self Scale and the structure of interpersonal closeness. Journal of Personality and Social Psychology, 63, 596-612. http://dx.doi.org/10.1037/0022-3514.63.4.596

Bates, D., Mächler, M., Bolker, B., \& Walker, S. (2015). lme4: Linear mixed-effects models using Eigen and S4. Journal of Statistical Software, 67, 1-48. http://dx. doi.org/10.18637/jss.v067.i01

Birkeland, R., Thompson, J. K., Herbozo, S., Roehrig, M., Cafri, G., \& van den Berg, P. (2005). Media exposure, mood, and body image dissatisfaction: An experimental test of person versus product priming. Body Image, 2, 53-61. http://dx.doi.org/10.1016/j.bodyim.2004.11.002

Bode, C., van der Heij, A., Taal, E., \& van de Laar, M. A. F. J. (2010). Body-self unity and self-esteem in patients with rheumatic diseases. Psychology, Health $\mathcal{\sigma}$ Medicine, 15, 672-684. http://dx.doi.org/10.1080/13548506.2010.507774

Brown, T. A., Cash, T. F., \& Mikulka, P. J. (1990). Attitudinal body-image assessment: Factor analysis of the Body-Self Relations Questionnaire. Journal of Personality Assessment, 55, 135-144. http://dx.doi.org/10.1207/s15327752jpa5501\&2_13

Cash, T. F., Jakatdar, T. A., \& Williams, E. F. (2004). The Body Image Quality of Life Inventory: Further validation with college men and women. Body Image, 1 , 279-287. http://dx.doi.org/10.1016/S1740-1445(03)00023-8

Cash, T. F. (2000). Multidimensional Body-Self Relations Questionnaire users' manual (3rd rev.). Available from:. www.body-images.com

Cash, T. F. (2011). Cognitive-behavioural perspectives on body image. In T. F. Cash \& L. Smolak (Eds.), Body image: A handbook of science, practice, and prevention (pp. 39-47). New York, NY: The Guilford Press.

Cook-Cottone, C., Kane, L. S., Keddie, E., \& Haugli, S. (2013). Girls growing in wellness and balance: Yoga and life skills to empower. Stoddard, WI: Schoolhouse Educational Services. 
Cooley, E., \& Toray, T. (2001). Body image and personality predictors of eating disorder symptoms during the college years. International Journal of Eating Disorders, 30, 28-36. http://dx.doi.org/10.1002/eat.1051

Eysenbach, G. (2005). The law of attrition. Journal of Medical Internet Research, 7, e11. http://dx.doi.org/10.2196/jmir.7.1

Fallon, E. A., Harris, B. S., \& Johnson, P. (2014). Prevalence of body dissatisfaction among a United States adult sample. Eating Behaviors, 15, 151-158. http://dx. doi.org/10.1016/j.eatbeh.2013.11.007

Franzoi, S. L., \& Herzog, M. E. (1986). The Body Esteem Scale: A convergent and discriminant validity study. Journal of Personality Assessment, 50, 24-31.

Franzoi, S. L., \& Shields, S. A. (1984). The Body Esteem Scale: Multidimensional structure and sex differences in a college population. Journal of Personality Assessment, 48, 173-178. http://dx.doi.org/10.1207/s15327752jpa4802_12

Fredrickson, B. L., \& Roberts, T.-A. (1997). Objectification theory: Toward understanding women's lived experiences and mental health risks. Psychology of Women Quarterly, 21, 173-206. http://dx.doi.org/10.1111/j.1471-6402.1997. tb00108.x

Frisén, A., \& Holmqvist, A. (2010). What characterizes early adolescents with a positive body image? A qualitative investigation of Swedish girls and boys. Body Image, 7, 205-212. http://dx.doi.org/10.1016/j.bodyim.2010.04.001

Goldenberg, J. L., \& Shackelford, T. I. (2005). Is it me or is it mine? Body-self integration as a function of self-esteem, body-esteem, and mortality salience. Self and Identity, 4, 227-241. http://dx.doi.org/10.1080/13576500444000254

Grabe, S., Ward, L. M., \& Hyde, J. S. (2008). The role of the media in body image concerns among women: A meta-analysis of experimental and correlational studies. Psychological Bulletin, 134, 460-476. http://dx.doi.org/10.1037/00332909.134.3.460

Graham, J. W., Olchowski, A. E., \& Gilreath, T. D. (2007). How many imputations are really needed? Some practical clarifications of multiple imputation theory. Prevention Science, 8, 206-213. http://dx.doi.org/10.1007/s11121-007-0070-9

Grogan, S. (2006). Body image and health: Contemporary perspectives. Journal of Health Psychology, 11, 523-530. http://dx.doi.org/10.1177/1359105306065013

Grund, S., Robitzsch, A., \& Luedtke, O. (2017). Mitml: tools for multiple imputation in multilevel modeling. $R$ package version 0 . pp. 3-5. Retrieved from:. https://cran. r-project.org/package=mitm

Halliwell, E. (2015). Future directions for positive body image research. Body Image, 14, 177-189. http://dx.doi.org/10.1016/j.bodyim.2015.03.003

Halliwell, E., Diedrichs, P. C., \& Orbach, S. (2014). Costing the invisible: A review of the evidence examining the links between body image, aspirations, education and workplace confidence. Discussion paper. Bristol: Centre for Appearance Research, University of the West of England. Available from:. http://eprints. uwe.ac.uk/24438/

Harrison, K. (2006). Scope of self: Toward a model of television's effects on self-complexity in adolescence. Communication Theory, 16, 251-279. http://dx. doi.org/10.1111/j.1468-2885.2006.00270. x

Hayes, A. F. (2006). A primer on multilevel modeling. Human Communication Research, 32, 385-410. http://dx.doi.org/10.1111/j.1468-2958.2006.00281.x

Heinberg, L. J., \& Thompson, J. K. (1995). Body image and televised images of thinness and attractiveness: A controlled laboratory investigation. Journal of Social and Clinical Psychology, 14, 325-338. http://dx.doi.org/10.1521/jscp. 1995.14.4.325

Koch, E. J., \& Shepperd, J. A. (2004). Is self-complexity linked to better coping? A review of the literature. Journal of Personality, 72, 727-760. http://dx.doi.org/ 10.1111/j.0022-3506.2004.00278. $x$

Linville, P. W. (1985). Self-complexity and affective extremity: Don't put all of your eggs in one cognitive basket. Social Cognition, 3, 94-120. http://dx.doi.org/10. 1521/soco.1985.3.1.94

Linville, P. W. (1987). Self-complexity as a cognitive buffer against stress-related illness and depression. Journal of Personality and Social Psychology, 52, 663-676. http://dx.doi.org/10.1037/0022-3514.52.4.663

MacKinnon, D. P., Lockwood, C. M., Hoffman, J. M., West, S. G., \& Sheets, V. (2002). A comparison of methods to test mediation and other intervening variable effects. Psychological Methods, 7, 83-104. http://dx.doi.org/10.1037/1082989X.7.1.83

Mahlo, L., \& Tiggemann, M. (2016). Yoga and positive body image: A test of the embodiment model. Body Image, 18, 135-142. http://dx.doi.org/10.1016/j. bodyim.2016.06.008

McHugh, T. F., Coppola, A. M., \& Sabiston, C. M. (2014). I'm thankful for being Native and my body is part of that: The body pride experiences of young Aboriginal women in Canada. Body Image, 11, 318-327. http://dx.doi.org/10. 1016/j.bodyim.2014.05.004
Meng, X.-L., \& Rubin, D. B. (1992). Performing likelihood ratio tests with multiply-imputed data sets. Biometrika, 79, 103-111. http://dx.doi.org/10. $2307 / 2337151$

Menzel, J. E., \& Levine, M. P. (2011). Embodying experiences and the promotion of positive body image: The example of competitive athletics. In R. M. Calogero, S Tantleff-Dunn \& J. K. Thompson (Eds.), Self-objectification in women: Causes, consequences, and counteractions (pp. 163-186). Washington, DC: American Psychological Association.

Morgan, H. J., \& Janoff-Bulman, R. (1994). Positive and negative self-complexity: Patterns of adjustment following traumatic versus non-traumatic life experiences. Journal of Social and Clinical Psychology, 13, 63-85. http://dx.doi. org/10.1521/jscp.1994.13.1.63

Mulgrew, K. E., Stalley, N. L., \& Tiggemann, M. (2017). Positive appearance and functionality reflections can improve body satisfaction but do not protect against idealised media exposure. Body Image, 23, 126-134. http://dx.doi.org/ 10.1016/j.bodyim.2017.09.002

Paxton, S. J., Neumark-Sztainer, D., Hannan, P. J., \& Eisenberg, M. E. (2006). Body dissatisfaction prospectively predicts depressive mood and low self-esteem in adolescent girls and boys. Journal of Clinical Child and Adolescent Psychology, 35 539-549. http://dx.doi.org/10.1207/s15374424jccp3504_5

Paxton, S. J. (2015). Social policy and prevention. In L. Smolak \& M. P. Levine (Eds.), The Wiley handbook of eating disorders. Chichester, UK: John Wiley \& Sons, Ltd.

Peugh, J. L. (2010). A practical guide to multilevel modeling. Journal of School Psychology, 48, 85-112. http://dx.doi.org/10.1016/j.jsp.2009.09.002

Piran, N. (2016). Embodied possibilities and disruptions: The emergence of the experience of embodiment construct from qualitative studies with girls and women. Body Image, 18, 43-60. http://dx.doi.org/10.1016/j.bodyim.2016.04. 007

R Core Team. (2015). R: A language and environment for statistical computing. Vienna, Austria.

Rosseel, Y. (2012). Lavaan: An R package for structural equation modeling. Journal of Statistical Software, 48, 1-36. http://dx. doi.org/10.18637/jss.v048.i02

Saguy, A. C., \& Ward, A. (2011). Coming out as fat: Rethinking stigma. Social Psychology Quarterly, 74, 53-75. http://dx.doi.org/10.1177/0190272511398190

Slater, A., \& Tiggemann, M. (2012). Time since menarche and sport participation as predictors of self-objectification: A longitudinal study of adolescent girls. Sex Roles, 67, 571-581. http://dx.doi.org/10.1007/s11199-012-0200-0

Swami, V., \& Tovée, M. J. (2009). A comparison of actual-weight discrepancy, body appreciation, and media influence between street-dancers and non-dancers. Body Image, 6, 304-307. http://dx.doi.org/10.1016/j.bodyim.2009.07.006

Swami, V. (2017). Sketching people: Prospective investigations of the impact of life drawing on body image. Body Image, 20, 65-73. http://dx.doi.org/10.1016/j. bodyim.2016.12.001

Teall, T., \& Piran, N. (2015). Embodiment Scales for Women: A Psychometric Study of the Experience of Embodiment Scale. In Poster presented at the American Psychological Association Annual Convention.

Thompson, J. K., Heinberg, L. J., Altabe, M., \& Tantleff-Dunn, S. (1999). Exacting beauty: Theory, assessment, and treatment of body image disturbance. Washington, DC: American Psychological Association.

Tiggemann, M., Coutts, E., \& Clark, L. (2014). Belly dance as an embodying activity? A test of the embodiment model of positive body image. Sex Roles, 71, 197-207. http://dx.doi.org/10.1007/s11199-014-0408-2

Tylka, T. L., \& Wood-Barcalow, N. L. (2015a). What is and what is not positive body image? Conceptual foundations and construct definition. Body Image, 1-12. http://dx.doi.org/10.1016/j.bodyim.2015.04.001

Tylka, T. L., \& Wood-Barcalow, N. L. (2015b). The Body Appreciation Scale-2: Item refinement and psychometric evaluation. Body Image, 12, 53-67. http://dx.doi. org/10.1016/j.bodyim.2014.09.006

van Buuren, S., \& Groothuis-Oudshoorn, K. (2011). \{mice\}: Multivariate imputation by chained equations in R. Journal of Statistical Software, 45, 1-67. http://dx.doi. org/10.18637/jss.v045.i03

Webb, J. B., Wood-Barcalow, N. L., \& Tylka, T. L. (2015). Assessing positive body image: Contemporary approaches and future directions. Body Image, 14, 130-145. http://dx.doi.org/10.1016/j.bodyim.2015.03.010

Wood-Barcalow, N. L., Tylka, T. L., \& Augustus-Horvath, C. L. (2010). But I like my body: Positive body image characteristics and a holistic model for young adult women. Body Image, 7, 106-116. http://dx.doi.org/10.1016/j.bodyim.2010.01. 001

Zhao, J.H., \& Schafer, J.L. (2016). pan: Multiple imputation for multivariate panel or clustered data. R Package version 1.4. Retrieved from https://cran.r-project. org/web/packages/pan/. 